\title{
Catechol glucosides act as donor/acceptor substrates of glucansucrase enzymes of Lactobacillus reuteri
}

\author{
Evelien M. te Poele ${ }^{1}$ • Vincent Valk ${ }^{1}$ - Tim Devlamynck ${ }^{1,2}$ - Sander S. van Leeuwen ${ }^{1}$. \\ Lubbert Dijkhuizen ${ }^{1}$
}

Received: 8 December 2016 / Revised: 5 February 2017 / Accepted: 12 February 2017 /Published online: 3 March 2017

(C) The Author(s) 2017. This article is published with open access at Springerlink.com

\begin{abstract}
Previously, we have shown that the glucansucrase GtfA- $\Delta \mathrm{N}$ enzyme of Lactobacillus reuteri 121, incubated with sucrose, efficiently glucosylated catechol and we structurally characterized catechol glucosides with up to five glucosyl units attached (te Poele et al. in Bioconjug Chem 27:937-946, 2016). In the present study, we observed that upon prolonged incubation of GtfA- $\Delta \mathrm{N}$ with $50 \mathrm{mM}$ catechol and $1000 \mathrm{mM}$ sucrose, all catechol had become completely glucosylated and then started to reappear. Following depletion of sucrose, this glucansucrase GtfA- $\Delta \mathrm{N}$ used both $\alpha$-D-Glcpcatechol and $\alpha$-D-Glc $p-(1 \rightarrow 4)-\alpha$-D-Glcp-catechol as donor substrates and transferred a glucose unit to other catechol glycoside molecules or to sugar oligomers. In the absence of sucrose, GtfA- $\Delta \mathrm{N}$ used $\alpha$-D-Glc $p$-catechol both as donor and acceptor substrate to synthesize catechol glucosides with 2 to 10 glucose units attached and formed glucooligosaccharides up to a degree of polymerization of 4 . Also two other glucansucrases tested, Gtf180- $\Delta \mathrm{N}$ from $L$. reuteri 180 and GtfML1- $\Delta \mathrm{N}$ from $L$. reuteri ML1, used $\alpha$-D-Glcpcatechol and di-glucosyl-catechol as donor/acceptor substrate to synthesize both catechol glucosides and gluco-
\end{abstract}

Electronic supplementary material The online version of this article (doi:10.1007/s00253-017-8190-z) contains supplementary material, which is available to authorized users.

Lubbert Dijkhuizen

1.dijkhuizen@rug.nl

1 Microbial Physiology Research Group, Groningen Biomolecular Sciences and Biotechnology Institute (GBB), University of Groningen, Groningen, The Netherlands

2 Centre for Industrial Biotechnology and Biocatalysis, Department of Biochemical and Microbial Technology, Faculty of Bioscience Engineering, Ghent University, Coupure Links 653, 9000 Ghent, Belgium oligosaccharides. With sucrose as donor substrate, the three glucansucrase enzymes also efficiently glucosylated the phenolic compounds pyrogallol, resorcinol, and ethyl gallate; also these mono-glucosides were used as donor/acceptor substrates.

Keywords Glucansucrase - Lactobacillus reuteri $\cdot$ Catechol glucosides $\cdot$ Acceptor reaction $\cdot$ Glucosyl donor

\section{Introduction}

Glucansucrases are large multi-domain extracellular enzymes that are classified into the glycoside hydrolase family 70 (GH70) (Lombard et al. 2014). They only have been detected in lactic acid bacteria, in members of the genera Leuconostoc, Streptococcus, Lactobacillus, and Weissella. Glucansucrases cleave the glycosidic bond of sucrose and transfer the glucose moiety to an acceptor substrate with release of the fructosyl moiety. Depending on the acceptor substrate, glucansucrases catalyze three types of reactions, i.e., polymerization, hydrolysis, and the acceptor reaction. In polymerization, the main reaction of glucansucrases, the glucose moiety is coupled to a growing chain of $\alpha$-glucan oligo- and polysaccharides. Depending on the glucansucrase enzyme, the $\alpha$-glucan products differ in linkage type, the type and degree of branching, and molecular mass. One kind, or a mixture of $(\alpha 1 \rightarrow 2)$, $(\alpha 1 \rightarrow 3),(\alpha 1 \rightarrow 4)$, or $(\alpha 1 \rightarrow 6)$ glycosidic linkages, may be found. The glucansucrase GtfA- $\Delta \mathrm{N}$ of Lactobacillus reuteri 121 (Kralj et al. 2002) produces a reuteran-type branched $\alpha$ glucan containing $58 \%(\alpha 1 \rightarrow 4)$ and $42 \%(\alpha 1 \rightarrow 6)$ glycosidic linkages and up to $14 \%$ branching (van Leeuwen et al. 2008b). When water is the acceptor substrate, glucansucrases hydrolyze sucrose into glucose and fructose. In the acceptor reaction the glucose unit is transferred to other carbohydrates than a 
growing $\alpha$-glucan chain, or to other hydroxyl-group containing organic molecules (Cote and Robyt 1982; Leemhuis et al. 2013). Glucansucrase enzymes are interesting biocatalysts for the glycosylation of small organic molecules, because they are promiscuous towards a wide range of acceptor substrates (Monsan et al. 2010; Leemhuis et al. 2012). Using inexpensive sucrose as glycosyl donor, glucansucrase enzymes glucosylate, for instance, phenolic compounds such as catechol (Meulenbeld and Hartmans 2000; Devlamynck et al. 2016; te Poele et al. 2016) and hydroquinone (Seo et al. 2009; Devlamynck et al. 2016), primary alcohols (Seibel et al. 2006; Devlamynck et al. 2016), and L-ascorbic acid (Kim et al. 2010). Glycosylation may change the physicochemical and biological properties of molecules, enhance bioavailability of antibiotics, or improve stability of molecules against auto-oxidation (Desmet et al. 2012). Recently, we characterized a series of catechol glucosides produced by GtfA- $\Delta \mathrm{N}$, after incubation with catechol and sucrose (te Poele et al. 2016). Catechol glucosides up to a degree of polymerization (DP) of 5, with different combinations of $(\alpha 1 \rightarrow$ $4)$ and $(\alpha 1 \rightarrow 6)$ linkages, were structurally characterized using 1D/2D ${ }^{1} \mathrm{H}$ NMR spectroscopy, and compared to $\alpha$-glucan structures synthesized by GtfA- $\Delta \mathrm{N}$ from sucrose only. Interesting similarities were found, but also clear structural differences. A branched catechol glucoside was identified and a catechol glucoside with two successive $(\alpha 1 \rightarrow 6)$ glycosidic linkages, structures that were not found when GtfA- $\Delta \mathrm{N}$ was incubated with sucrose only (te Poele et al. 2016).

In this study, we analyzed the glucosylation of phenolic compounds by the GtfA- $\Delta \mathrm{N}$, and by two related $L$. reuteri glucansucrase enzymes Gtf180- $\Delta \mathrm{N}$ and GtfML1- $\Delta \mathrm{N}$ (both having $78 \%$ amino acid identity to GtfA- $\Delta \mathrm{N}$ (Kralj et al. 2004a)), in more detail. All three enzymes can efficiently synthesize mono-glucosylated catechol (catG1), pyrogallol, resorcinol, and ethyl-gallate, and subsequently reuse these compounds as glucosyl donor. Incubation of GtfA- $\Delta N$ with mono-glucosylated catechol synthesized catechol glucosides with up to 10 glucose units. GtfA- $\Delta \mathrm{N}$ could also use $\alpha$-DGlc $p$ - $(1 \rightarrow 4)-\alpha$-D-Glc $p$-catechol ( cat $\left.^{4} \mathrm{G} 2\right)$ as donor substrate. Gtf180- $\Delta \mathrm{N}$ could use $\alpha$-D-Glc $p$ - $(1 \rightarrow 3)-\alpha$-D-Glc $p$-catechol $\left(\right.$ cat $\left.^{3} \mathrm{G} 2\right)$ and $\alpha$-D-Glc $p-(1 \rightarrow 6)-\alpha-\mathrm{D}-\mathrm{Glc} p$-catechol (cat ${ }^{6} \mathrm{G} 2$ ) as donor substrates. GtfML1- $\Delta \mathrm{N}$ was unable to use any of the catG2 substrates as glucosyl donor.

\section{Materials and methods}

\section{Purification of recombinant glucansucrase enzymes}

Recombinant, N-terminally truncated GtfA- $\Delta \mathrm{N}$ of $L$. reuteri 121 (Kralj et al. 2004b), Gtf180- $\Delta \mathrm{N}$ of L. reuteri 180 (Kralj et al. 2004a), and GtfML1- $\Delta \mathrm{N}$ of $L$. reuteri ML1 (Kralj et al. 2004a) were produced and purified as described previously
(Kralj et al. 2004b; Meng et al. 2014). The purity of the enzymes was checked by SDS-PAGE, and enzyme concentrations were measured by absorbance at $280 \mathrm{~nm}$ using a NanoDrop 2000 spectrophotometer (Isogen Life Science, De Meern, The Netherlands).

\section{Standard reaction buffer}

All enzymatic reactions were performed at $37{ }^{\circ} \mathrm{C}$ in reaction buffer containing $25 \mathrm{mM}$ sodium acetate (pH 4.7) and $1 \mathrm{mM}$ $\mathrm{CaCl}_{2}$, unless stated otherwise.

\section{Enzyme activity assays with sucrose as both glucosyl donor and acceptor substrate}

To confirm activity of the glucansucrase enzymes after purification, enzyme activity assays were done in reaction buffer containing $100 \mathrm{mM}$ sucrose and $0.125 \mathrm{mg} / \mathrm{mL}$ purified protein. For this, samples of $100 \mu \mathrm{L}$ were taken every $30 \mathrm{~s}$ for $4 \mathrm{~min}$ and directly inactivated by adding $20 \mu \mathrm{L}$ of $1000 \mathrm{mM}$ $\mathrm{NaOH}$ for $30 \mathrm{~min}$. The inactivated samples were diluted two times in deionized water, and from $10 \mu \mathrm{L}$ of the diluted samples, the glucose and fructose were quantified enzymatically by monitoring the reduction of NADP as described previously (Mayer 1987). The release of fructose corresponds to the total enzyme activity, the release of glucose corresponds to the hydrolytic activity, and the amount of fructose minus the amount of glucose corresponds to the transglycosylation activity (van Geel-Schutten et al. 1999). One unit (U) of enzyme is defined as the amount of enzyme required for producing $1 \mu \mathrm{mol}$ fructose monosaccharide or catechol (glucoside) per min. Accordingly, the activities of GtfA- $\Delta \mathrm{N}$, Gtf180- $\Delta \mathrm{N}$, and GtfMLI- $\Delta \mathrm{N}$ were $26.7,12.3$, and $9.5 \mathrm{U} / \mathrm{mg}$ purified enzyme, respectively.

To determine the activity of GtfA- $\Delta \mathrm{N}$ on sucrose as both glucosyl donor and acceptor substrate, enzyme activity assays were done with six different sucrose concentrations ranging from 3.1 to $100 \mathrm{mM}$, in reaction buffer and $0.125 \mathrm{mg} / \mathrm{mL}$ GtfA- $\Delta N$, and performed as described above. Kinetic parameters were calculated by non-linear regression of the Michaelis-Menten equation with SigmaPlot v12.0.

\section{Enzyme activity assays with catechol glucosides as both glucosyl donor and acceptor substrate}

$\alpha$-D-Glc $p$-catechol (catG1) and $\alpha$-D-Glc $p$ - $(1 \rightarrow 4)-\alpha$-D-Glc $p$ catechol ( cat $^{4} \mathrm{G} 2$ ) synthesized by GtfA- $\Delta \mathrm{N}$ (te Poele et al. 2016), and $\alpha$-D-Glc $p-(1 \rightarrow 3)-\alpha-\mathrm{D}-$ Glc $p$-catechol (cat $\left.{ }^{3} \mathrm{G} 2\right)$ and $\alpha$-D-Glc $p$ - $(1 \rightarrow 6)-\alpha$-D-Glc $p$-catechol (cat ${ }^{6} \mathrm{G} 2$ ) synthesized by Gtf180- $\Delta \mathrm{N}$ (Devlamynck et al. 2016), were isolated and purified using preparative normal-phase HPLC (NP-HPLC) as described previously (te Poele et al. 2016). GtfA- $\Delta \mathrm{N}$ enzyme activity on catG1 was measured at six different catG1 
concentrations ranging from 3.1 to $100 \mathrm{mM}$ using $0.125 \mathrm{mg} /$ $\mathrm{mL}$ GtfA- $\Delta \mathrm{N}$. The activities of GtfA- $\Delta \mathrm{N}, \mathrm{Gtf} 180-\Delta \mathrm{N}$, and GtfMLI- $\Delta N$ on catechol di-glucosides were measured at $100 \mathrm{mM}$ cat $^{3} \mathrm{G} 2$, cat ${ }^{4} \mathrm{G} 2$, and cat ${ }^{6} \mathrm{G} 2$ in reaction buffer and $1.25 \mathrm{mg} / \mathrm{mL}$ enzyme. Samples were taken every minute over a period of 9 and $12 \mathrm{~min}$ for catG1 and catG2, respectively, immediately inactivated by diluting a $10 \mu \mathrm{L}$ sample in $250 \mu \mathrm{L}$ of $80 \%$ methanol, and centrifuged for $2 \mathrm{~min}$ at $15,000 \times g$. Total activity of GtfA- $\Delta \mathrm{N}$ on catG1 was determined by measuring the release of catechol from catG1, and the activities of the enzymes on catG2 were measured by the decrease of catG2. Catechol-, catG1-, cat $^{3} \mathrm{G} 2-$, cat $^{4} \mathrm{G} 2-$, and cat $^{6} \mathrm{G} 2$-concentrations were determined with NP-HPLC, using their corresponding calibration curves ranging from 1.56 to $100 \mathrm{mM}$.

\section{Enzymatic sucrose detection}

Catechol acceptor reactions were heat inactivated at $100{ }^{\circ} \mathrm{C}$ for $15 \mathrm{~min}$. Inactivated samples were diluted 100 times in deionized water. From the diluted sample, $10 \mu \mathrm{L}$ was incubated in a total volume of $50 \mu \mathrm{L}$ of $100 \mathrm{mM} \mathrm{NaOAc}(\mathrm{pH} 5.5)$ with and without $2 \mu \mathrm{L}$ invertase (BDH Chemicals; catalog number 390203D), to convert sucrose into glucose and fructose. The glucose and fructose were quantified as described above. The amount of remaining sucrose in the samples can be measured by subtracting the amount of glucose in the nontreated samples from the amount of glucose in the invertasetreated samples.

\section{Enzymatic glucosylation of catechol}

To follow catechol glucosylation by GtfA- $\Delta \mathrm{N}$ in time, incubation reactions were carried out in reaction buffer with $50 \mathrm{mM}$ catechol (1,2-dihydroxybenzene, $>99 \%$ pure, SigmaAldrich), $1000 \mathrm{mM}$ sucrose, and $0.5 \mathrm{mg} / \mathrm{mL}$ purified GtfA- $\Delta \mathrm{N}$ enzyme for $4 \mathrm{~h}$. Samples were taken after 0, 30, $60,80,105,135$, and $240 \mathrm{~min}$ and were directly heat inactivated at $100{ }^{\circ} \mathrm{C}$ for $15 \mathrm{~min}$. For NP-HPLC analysis, $10 \mu \mathrm{L}$ samples were diluted in $250 \mu \mathrm{L}$ of $80 \% \mathrm{MetOH}$ and centrifuged for $2 \mathrm{~min}$ at $15,000 \times g$.

\section{Use of catechol glucosides as donor substrates}

The use of catechol glucosides as donor substrate was followed in time, using incubation reactions with $50 \mathrm{mM}$ catG1 in reaction buffer and $0.250 \mathrm{mg} / \mathrm{mL}$ purified GtfA- $\Delta \mathrm{N}$ enzyme. After $1 \mathrm{~h}, 200 \mathrm{mM}$ sucrose was added and the mixture was incubated for an additional $1 \mathrm{~h}$. Samples were taken at $0,10,30$, and $60 \mathrm{~min}$ (just before addition of $200 \mathrm{mM}$ sucrose), 70, 90, and $120 \mathrm{~min}$, and immediately heat inactivated at $100{ }^{\circ} \mathrm{C}$ for $15 \mathrm{~min}$. For NP-HPLC analysis, $10 \mu \mathrm{L}$ sample was diluted in $250 \mu \mathrm{L}$ of $80 \% \mathrm{MetOH}$ and centrifuged for $2 \mathrm{~min}$ at $15,000 \times \mathrm{g}$. Twenty-four-hour incubations of reaction buffer containing $100 \mathrm{mM}$ catG1 without enzyme or with $1.25 \mathrm{mg} / \mathrm{mL}$ GtfA- $\Delta N$, Gtf180- $\Delta N$, and GtfMLI- $\Delta N$ were analyzed with MALDI-TOF-MS. For NMR spectroscopy analysis of glucosidic linkages in GtfA- $\Delta N$ products from incubations with catG1 $(100 \mathrm{mM})$ with and without sucrose (1000 $\mathrm{mM})$, two 60-min incubations were done with reaction buffer containing $0.5 \mathrm{mg} / \mathrm{mL}$ GtfA- $\Delta \mathrm{N}$. NMR analysis was also performed on 60-min incubations of reaction buffer containing $0.5 \mathrm{mg} / \mathrm{mL}$ GtfA- $\Delta \mathrm{N}$ and $100 \mathrm{mM}$ cat $^{4} \mathrm{G} 2,0.5 \mathrm{mg} / \mathrm{mL}$ Gtf180- $\Delta \mathrm{N}$ and $100 \mathrm{mM}$ cat $^{3} \mathrm{G} 2$, and $0.5 \mathrm{mg} / \mathrm{mL}$ Gtf180- $\Delta \mathrm{N}$ and $100 \mathrm{mM}^{\mathrm{cat}}{ }^{6} \mathrm{G} 2$. The catechol glucosides were purified from the reaction mixture by solid-phase extraction using Strata-X 33u Polymeric Reversed Phase columns (Phenomenex) and analyzed by 1D ${ }^{1}$ H NMR spectroscopy.

\section{Normal-phase HPLC (NP-HPLC)}

All NP-HPLC analyses were performed on an UltiMate 3000 chromatography system (Thermo Fisher Scientific, Amsterdam, The Netherlands), equipped with an UltiMate 3000 VWD 3100 UV detector and an Endurance autosampler (Spark Holland, The Netherlands). Catechol and catechol glucoside peaks were detected at $276 \mathrm{~nm}$. In all cases, a mobile phase of acetonitrile (solvent $\mathrm{A}$ ) and $50 \mathrm{mM}$ ammonium formate buffer, $\mathrm{pH} \mathrm{4.4,} \mathrm{(solvent} \mathrm{B)}$ was used. To follow in time the glucosylation and deglucosylation of catechol (glucosides) by GtfA- $\Delta \mathrm{N}$, reaction components were separated by injecting $40 \mu \mathrm{L}$ diluted sample on a Luna $\mathrm{NH}_{2}$ chromatography column (250 mm $\times 10 \mathrm{~mm}, 10 \mu \mathrm{m}$ particle size, Phenomenex) at a flow rate of $4.6 \mathrm{~mL} / \mathrm{min}$. Runs were started with a 5 -min isocratic step of $90 \%$ solvent A followed by a linear gradient from 90 to $60 \%$ solvent A over 17 min. All other NPHPLC analyses were performed on a Luna $\mathrm{NH}_{2}$ chromatography column $(250 \mathrm{~mm} \times 4.6 \mathrm{~mm}, 10 \mu \mathrm{m}$ particle size, Phenomenex) at a flow rate of $1 \mathrm{~mL} / \mathrm{min}$. To follow the activity of GtfA- $\Delta \mathrm{N}$ on catG1 over time, $20 \mu \mathrm{L}$ sample was injected and runs were started with a 5-min isocratic step of $90 \%$ solvent A followed by a linear gradient from 90 to $60 \%$ solvent A over $17 \mathrm{~min}$. Samples $(20 \mu \mathrm{L})$ of the deglucosylation of different mono-glucosylated phenolics using GtfA- $\Delta \mathrm{N}$, Gtf180- $\Delta \mathrm{N}$, and GtfMLI- $\Delta \mathrm{N}$ were started with a 2 -min isocratic step of $80 \%$ solvent $A$ followed by a linear gradient from 80 to $67 \%$ solvent A over 5 min and a final washing step of 3 min with $20 \%$ solvent A. Samples $(20 \mu \mathrm{L})$ of the 60 -min incubation of GtfA- $\Delta \mathrm{N}$ with cat ${ }^{4} \mathrm{G} 2$ were started with a 2 -min isocratic step of $80 \%$ solvent A followed by a linear gradient from 80 to $55 \%$ solvent A over $12 \mathrm{~min}$. 


\section{High-pH anion-exchange chromatography (HPAEC)}

Incubations of $30 \mathrm{~min}$ of $1.25 \mathrm{mg} / \mathrm{mL}$ GtfA- $\Delta \mathrm{N}$ and $1000 \mathrm{mM}$ sucrose with and without $50 \mathrm{mM}$ catechol were heat inactivated for $15 \mathrm{~min}$ and analyzed with HPAEC with pulsed amperometric detection (PAD). Samples were diluted 100 times in deionized water, and $25 \mu \mathrm{L}$ of the dilutions was run on a CarboPac PA-1 column $(250 \mathrm{~mm} \times 4 \mathrm{~mm}$, Dionex BV, Amsterdam, The Netherlands), using an ICS3000 Ion chromatograph (Dionex BV), equipped with an ICS3000 electrochemical detection cell for PAD with a gold working electrode (pulse potentials and durations: $\mathrm{E} 1=+0.1 \mathrm{~V}, 410 \mathrm{~ms} ; \mathrm{E} 2=-2.0 \mathrm{~V}$, $20 \mathrm{~ms}$; E3 $=+0.6 \mathrm{~V}, 10 \mathrm{~ms}$; E4 $=-0.1 \mathrm{~V}, 60 \mathrm{~ms})$. A 45-min linear gradient of $30-300 \mathrm{mM} \mathrm{NaOAc}$ in $100 \mathrm{mM} \mathrm{NaOH}$ $(1 \mathrm{~mL} / \mathrm{min})$ was used.

\section{MALDI-TOF-MS}

Experiments were performed on an Axima Performance ${ }^{\mathrm{TM}}$ mass spectrometer (Shimadzu Kratos Inc., Manchester, UK) equipped with a nitrogen laser ( $337 \mathrm{~nm}, 3 \mathrm{~ns}$ pulse width). Positive-ion mode spectra were recorded using the reflector mode at a resolution of at least 5000 Full Width at Half Maximum (FWHM) and acquired with software-controlled pulse-delayed extraction optimized for $m / z$ 1500. Mass spectra were recorded from 1 to $5000 \mathrm{~m} / z$, with ion-gate blanking set to $200 \mathrm{~m} / \mathrm{z}$. Samples were prepared by mixing $1 \mu \mathrm{L}$ enzymatic reaction mixture with $1 \mu \mathrm{L}$ of $10 \mathrm{mg} / \mathrm{mL} 2,5$-dihydroxybenzoic acid in $70 \% \mathrm{ACN}$ as matrix solution.

\section{NMR spectroscopy}

One- and two-dimensional ${ }^{1} \mathrm{H}$ and ${ }^{13} \mathrm{C}$ NMR spectra, including ${ }^{1} \mathrm{H}-{ }^{1} \mathrm{H}$ and ${ }^{13} \mathrm{C}-{ }^{1} \mathrm{H}$ correlation spectra, were recorded at a probe temperature of $25^{\circ} \mathrm{C}$ on a Varian Inova 600 spectrometer (NMR
Department, University of Groningen, The Netherlands). Onedimensional $600-\mathrm{MHz}{ }^{1} \mathrm{H}$ NMR spectra were recorded with $4800 \mathrm{~Hz}$ spectral width at 16k complex data points, using a WET1D suppression of the HOD signal. Two-dimensional ${ }^{1} \mathrm{H}-{ }^{1} \mathrm{H}$ COSY spectra were recorded in 256 increments of 4000 complex data points with a spectral width of $4800 \mathrm{~Hz}$. Twodimensional ${ }^{1} \mathrm{H}-{ }^{1} \mathrm{H}$ TOCSY spectra were recorded with MLEV17 mixing sequences with 50- and 150-ms spin-lock times. Two-dimensional ${ }^{13} \mathrm{C}-{ }^{1} \mathrm{H} H S Q C$ and $\mathrm{HMBC}$ spectra were recorded with a spectral width of $4800 \mathrm{~Hz}$ in $t_{2}$ and $10,000 \mathrm{~Hz}$ in $t_{1}$ direction, using 128 increments of 2000 complex points. Onedimensional ${ }^{13} \mathrm{C}$ NMR spectra were recorded in a $10,000 \mathrm{~Hz}$ spectral width, collecting 8000 transients of $32 \mathrm{k}$ complex points. All spectra were processed using MestReNov. 5.3 (Mestrelabs Research SL, Santiago de Compostela, Spain).

\section{Results}

\section{Synthesis of catechol glucosides using the GtfA- $\Delta N$ enzyme}

Previously, we showed that the transglycosylation/hydrolysis ratio of GtfA- $\Delta \mathrm{N}$ and its overall transglycosylation activity increased with increasing sucrose concentrations (te Poele et al. 2016). A 20 -fold increase in transglucosylation activity was observed when the sucrose concentration was increased from 3.1 to $1000 \mathrm{mM}$, i.e., from 2.1 to $39.8 \mu \mathrm{mol} / \mathrm{min} / \mathrm{mg}$ GtfA- $\Delta \mathrm{N}$. Therefore, $1000 \mathrm{mM}$ sucrose was used as glucosyl donor in the catechol acceptor reactions. Incubations of $0.5 \mathrm{mg} / \mathrm{mL}$ GtfA- $\Delta \mathrm{N}$ with $1000 \mathrm{mM}$ sucrose and $50 \mathrm{mM}$ catechol were followed in time (Figs. 1 and 2). After $30 \mathrm{~min}$, all chatechol was converted, revealing multiple catechol glucoside product peaks detectable at $276 \mathrm{~nm}$ (Fig. 1). Interestingly, when sucrose was depleted at $t=105 \mathrm{~min}$
Fig. 1 NP-HPLC product profiles $(276 \mathrm{~nm})$ of an incubation of $0.5 \mathrm{mg} / \mathrm{mL}$ GtfA- $\Delta \mathrm{N}$ with $50 \mathrm{mM}$ catechol and $1000 \mathrm{mM}$ sucrose, incubated for $0,30,60$, $80,105,135$, and $240 \mathrm{~min}$. Asterisk catechol peak at $4 \mathrm{~min}$; double asterisks catG1 peak at $13.3 \mathrm{~min}$ in the gray area; triple asterisks cat ${ }^{4} \mathrm{G} 2$ and cat $^{6} \mathrm{G} 2$ peaks at 17.3 and $18.7 \mathrm{~min}$, respectively

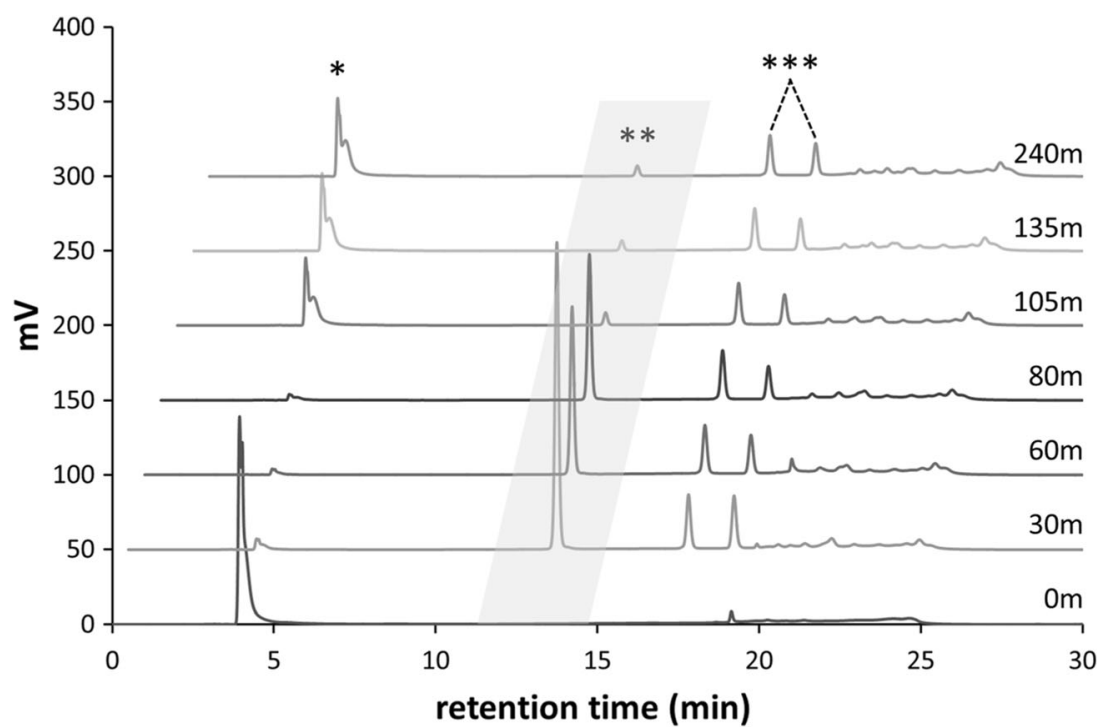


Fig. 2 Graph showing the sucrose (filled circle) conversion and fructose (filled square) release during incubation of $0.5 \mathrm{mg} / \mathrm{mL}$ GtfA- $\Delta \mathrm{N}$ with $50 \mathrm{mM}$ catechol and $1000 \mathrm{mM}$ sucrose for $240 \mathrm{~min}$. No significant glucose (filled triangle) release was detected. The data represent the means of three independent enzymatic carbohydrate detection assays. Error bars are \pm 1 standard deviation

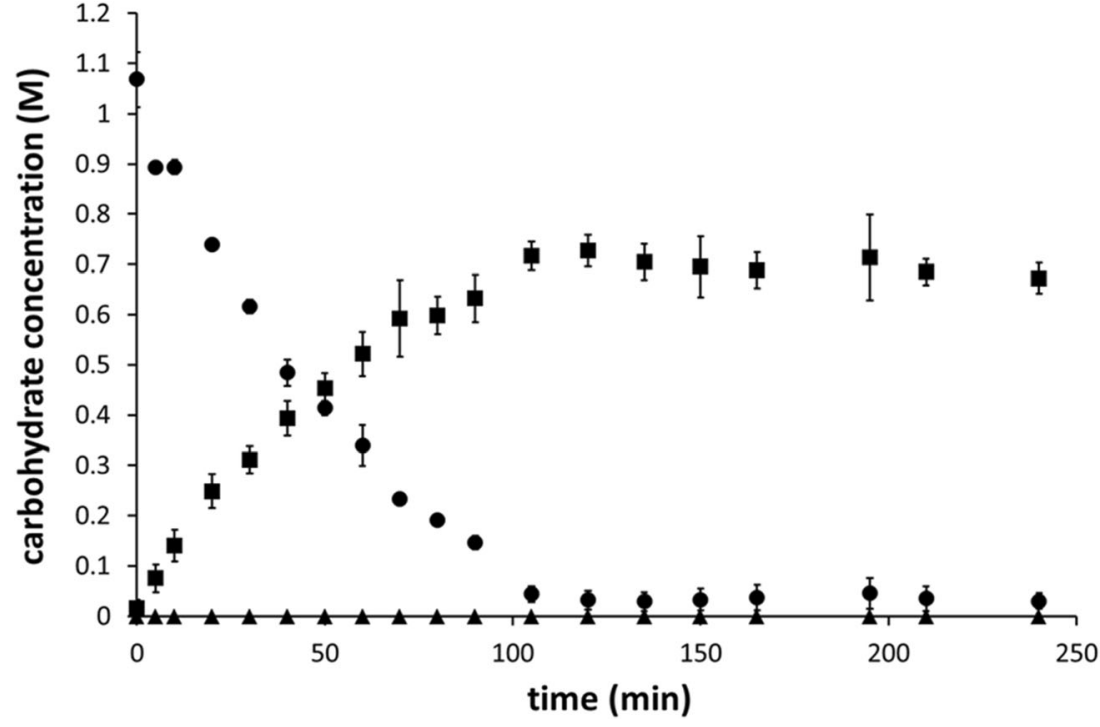

(Figs. 1 and 2), catechol reappeared, while the catG1 (te Poele et al. 2016) decreased. The catechol di-glucosides (te Poele et al. 2016) increased however, suggesting that transglycosylation occurred with catG1 as donor substrate. No detectable amounts of free glucose were found during these incubations (Fig. 2), suggesting that hydrolysis was negligible and all glucose from sucrose was used for synthesis of catechol glucosides and oligosaccharides (Supplemental material, Fig. S1). About $70 \%$ of the fructose was released (Fig. 2), showing that the other $30 \%$, as fructose or as part of sucrose, served as acceptor molecule for glucosylation and was incorporated into leucrose and oligosaccharides (with terminal fructose units).

\section{GtfA- $\Delta \mathrm{N}$ uses catG1 as glucosyl donor/acceptor substrate}

To test whether GtfA- $\Delta \mathrm{N}$ can use catG1 as glucosyl donor, $0.5 \mathrm{mg} / \mathrm{mL}$ GtfA- $\Delta \mathrm{N}$ was incubated with $50 \mathrm{mM}$ purified
catG1 as sole substrate. As shown in Fig. 3, the amount of catG1 decreased during the 60-min incubation, catechol was released, and catechol glucosides with higher DP were produced. These data clearly show that catG1 acted both as donor and acceptor substrate; i.e., the glucose moieties of the catG1 donor substrate were transferred to catG1 acceptor molecules, resulting in formation of catechol glucosides of DP2 and higher. Addition of $200 \mathrm{mM}$ sucrose to the 60 -min catG1 incubation resulted again in glucosylation of catechol into catG1, as can be observed by the disappearance of catechol and the formation of catG1 after $10 \mathrm{~min}$ incubation (Fig. 3). After $70 \mathrm{~min}$, sucrose was depleted (not shown) and the newly synthesized catG1 was again used as glucosyl donor resulting in the formation of catechol and larger catechol glucosides.

The transfer of glucose from catG1 to form multiglucosylated catechol molecules was confirmed by MALDI-TOF-MS (Supplemental material, Fig. S2). After $24 \mathrm{~h}$ incubation of GtfA- $\Delta \mathrm{N}$ with catG1, molecular masses
Fig. 3 NP-HPLC product profiles $(276 \mathrm{~nm})$ of an incubation of $0.25 \mathrm{mg} / \mathrm{mL}$ GtfA- $\Delta \mathrm{N}$ with $50 \mathrm{mM}$ catG1 for $t=0,30$, and $60 \mathrm{~min}$ without sucrose and at $t=70,90$, and $120 \mathrm{~min}$ after the addition of $200 \mathrm{mM}$ sucrose at $60 \mathrm{~min}$. Asterisk catechol; double asterisks catG1 (in the gray area); triple asterisks catG2

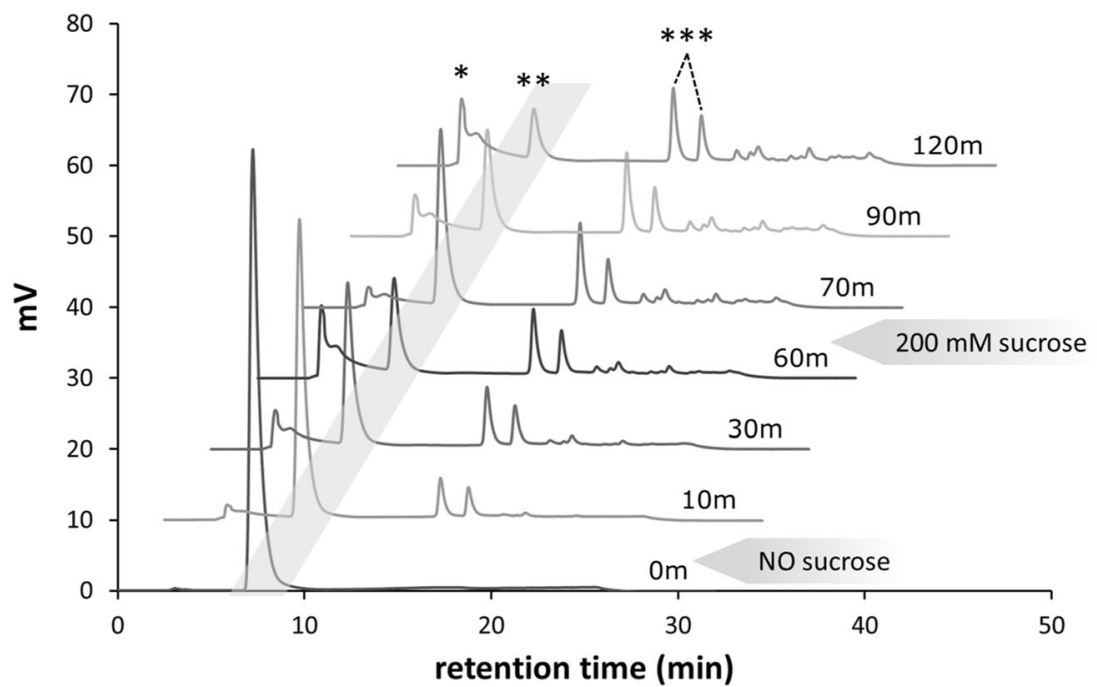


up to a degree of polymerization of 10 glucose units (sodium adduct at $1755.18 \mathrm{~m} / \mathrm{z}$ ) could be detected. Besides catechol glucosides, oligosaccharides up to DP4 were synthesized $(364.83,526.84$, and $688.98 \mathrm{~m} / \mathrm{z})$. The Gtf1 $180-\Delta \mathrm{N}$ and GtfMLI- $\Delta \mathrm{N}$ glucansucrase enzymes also were able to use catG1 as glucosyl donor, resulting in similar MALDITOF-MS product profiles with multi-glucosylated catechol (Supplemental material, Fig. S2). With sucrose as donor substrate, GtfA- $\Delta \mathrm{N}$, Gtf180- $\Delta \mathrm{N}$, and GtfMLI- $\Delta \mathrm{N}$ also efficiently glucosylated the phenolic compounds resorcinol, pyrogallol, and ethyl gallate (data not shown) and used their mono-glucosides, resG1 (Devlamynck et al. 2016), pyrG1 (Supplemental material, Table S1 and Fig. S3), and etgaG1 (Supplemental material, Table S1 and Fig. S4) as glucosyl donor/acceptor substrates (Supplemental material, Fig. S5).

\section{GtfA- $\Delta$ N enzyme kinetics with sucrose and catG1 as glucosyl donor/acceptor substrates}

The kinetics of GtfA- $\Delta \mathrm{N}$ with sucrose and catG1 as substrates was studied in more detail. For this, GtfA- $\Delta \mathrm{N}$ was incubated with different concentrations sucrose and catG1. Compared to the initial reaction rate of GtfA- $\Delta \mathrm{N}$ on $100 \mathrm{mM}$ sucrose, the rate on $100 \mathrm{mM}$ catG1 was $\sim 4$-fold lower (Fig. 4). GtfA- $\Delta \mathrm{N}$ displayed Michaelis Menten kinetics at sucrose and catG1 concentrations below $100 \mathrm{mM}$. The affinity $\left(k_{\mathrm{M}}\right)$ values of GtfA- $\Delta \mathrm{N}$ for sucrose and catG1 were determined as 9.7 and $44 \mathrm{mM}$, respectively. The maximum velocities $\left(V_{\max }\right)$ were 28.5 and $10.5 \mathrm{U} / \mathrm{mg}$ GtfA- $\Delta \mathrm{N}$ for sucrose and catG1, respectively.

The GtfA- $\Delta$ N product spectrum with $100 \mathrm{mM}$ catG1 as sole substrate was compared with the product spectrum using $100 \mathrm{mM}$ catG1 in the presence of $1000 \mathrm{mM}$ sucrose. The resulting catechol glucoside mixtures were analyzed by $1 \mathrm{D}{ }^{1} \mathrm{H}$ NMR spectroscopy (Fig. 5a, b) and NP-HPLC profiling (data not shown). Incubation with catG1 in the presence of sucrose resulted only in minor amount $(7.3 \%$ based on NMR integrals $x$ and $1 / 2 z$ of free catechol) (structural-reporter-group peaks $z$ in Fig. 5a; Fig. 6), fitting with the clearly higher catalytic efficiency with sucrose as donor substrate (Fig. 4). With catG1 alone, a large amount (56.4\% based on NMR integrals $x$ and $1 / 2 z$ ) of free catechol was formed (Fig. 5b). Both $1 \mathrm{D}{ }^{1} \mathrm{H}$ NMR spectra (Fig. 5a, b) showed structural-reporter-group signals a-f(Fig. 6), based on previous studies (Devlamynck et al. 2016; te Poele et al. 2016). When comparing the two $1 \mathrm{D}{ }^{1} \mathrm{H}$ NMR spectra, a notable difference in the ratio of peaks $b$ and $c$ was observed. Peaks in region $\mathrm{b}$ could be assigned to $\alpha$-DGlc $p$ - $(1 \rightarrow 4)$ residues that are linked to the first glucose residue after catechol, irrespective of further substitution (Fig. 6). Peak f corresponds with a 4-substituted Glc residue, which is linked to the catechol residue. The intensity of peak $f$ matches that of peak $b$ in both $1 D^{1} \mathrm{H}$ NMR spectra, indicating that mainly cat $^{4} \mathrm{G} 2$ core structures are formed. Peaks in region c correspond with $\alpha-\mathrm{D}-\mathrm{Glc} p-(1 \rightarrow$ 4) elements in different configurations further down the chain at longer DPs. Peak e corresponds with $\alpha$-DGlc $p-(1 \rightarrow 6)$ residues linked to the first Glc residue after catechol, whereas peak $\mathrm{d}$ belongs to $\alpha$-D-Glc $p$ - $(1 \rightarrow 6)$ residues further down the chain in longer DPs. In the incubation with catG1 alone, peaks $d$ and e have similar intensities, whereas the incubation with catG1 plus sucrose resulted in a much higher $d$ peak. The $(\alpha 1 \rightarrow 4) /(\alpha 1 \rightarrow 6)$ product ratios in the incubation with and without sucrose were 58:42 and 55:45, respectively.
Fig. 4 Effects of glucosyl donor substrate concentration, sucrose (filled triangle) and catG1 (filled circle), on initial GtfA- $\Delta \mathrm{N}$ enzyme activity in reaction buffer and $0.125 \mathrm{mg} / \mathrm{mL}$ GtfA- $\Delta \mathrm{N}$ at $37^{\circ} \mathrm{C}$ and $\mathrm{pH}$ 4.7. Error bars are \pm 1 standard deviation

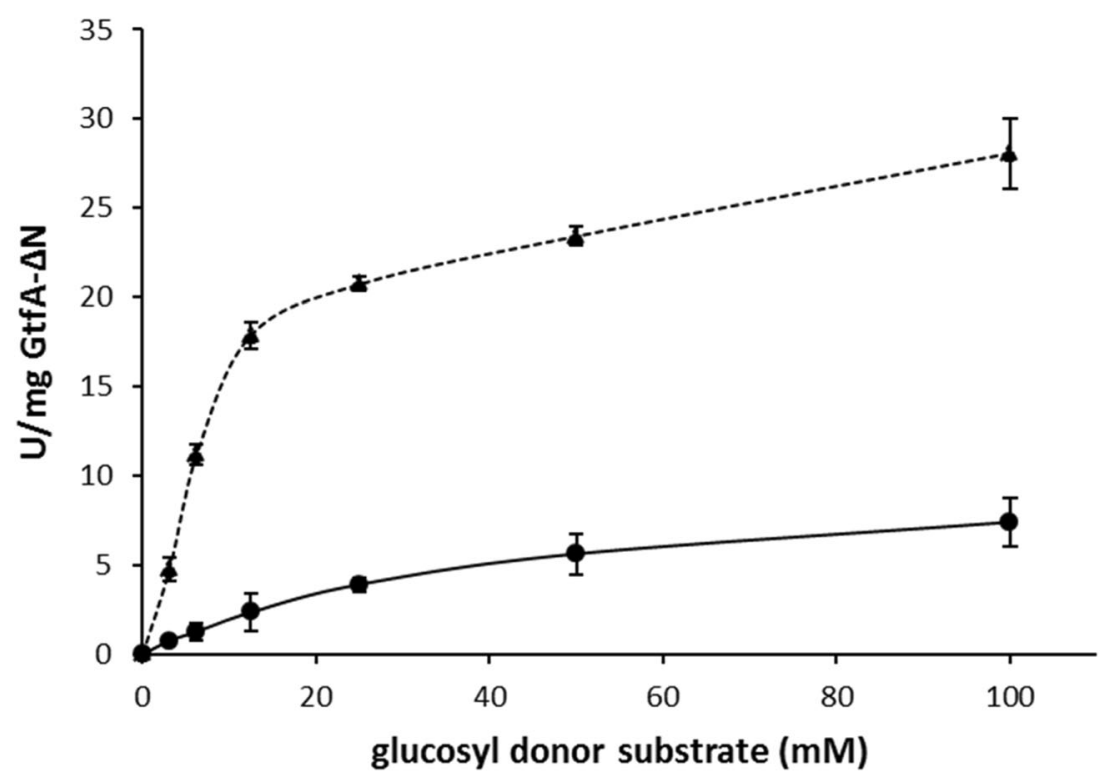


A GtfA- $\Delta \mathrm{N} ; 100 \mathrm{mM}$ catG1; $1,000 \mathrm{mM}$ sucrose

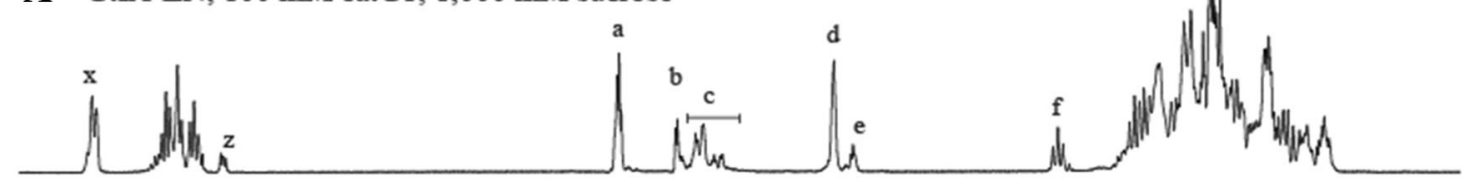

B GtfA- $\Delta \mathrm{N} ; 100 \mathrm{mM}$ catG1

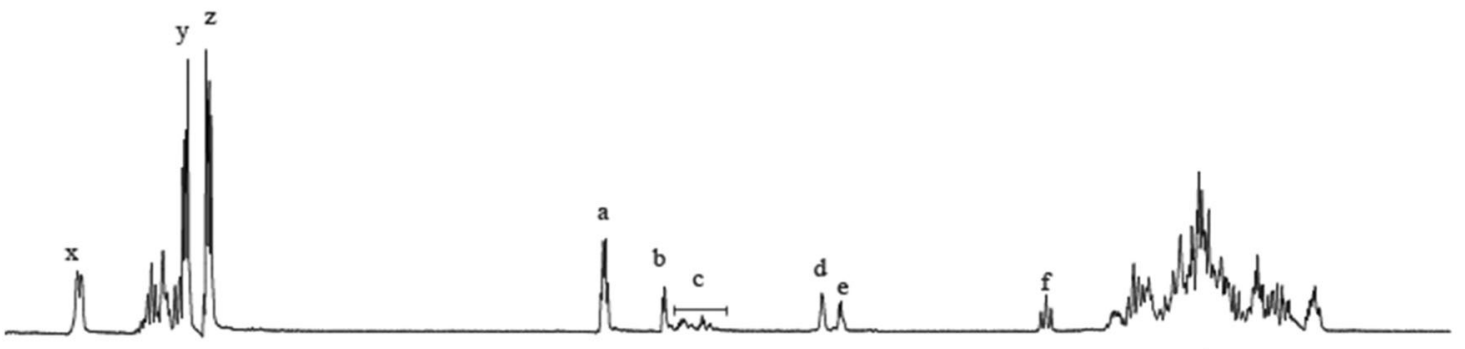

C GtfA- $\Delta \mathrm{N} ; \mathrm{Cat}^{4} \mathrm{G} 2$
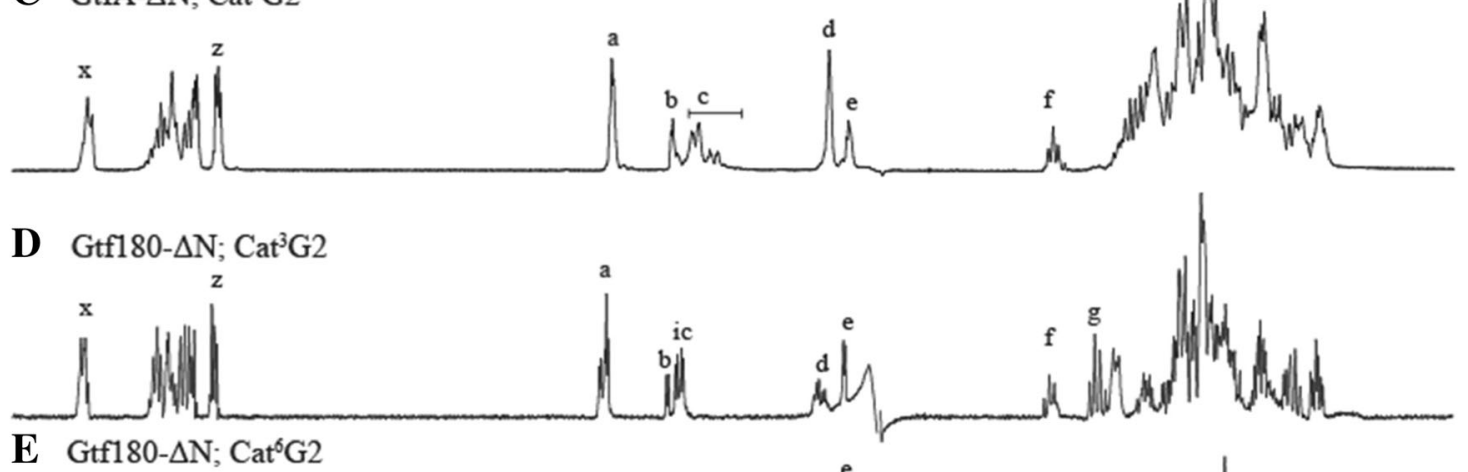

E Gtf180- $\Delta \mathrm{N} ; \mathrm{Cat}^{6} \mathrm{G} 2$

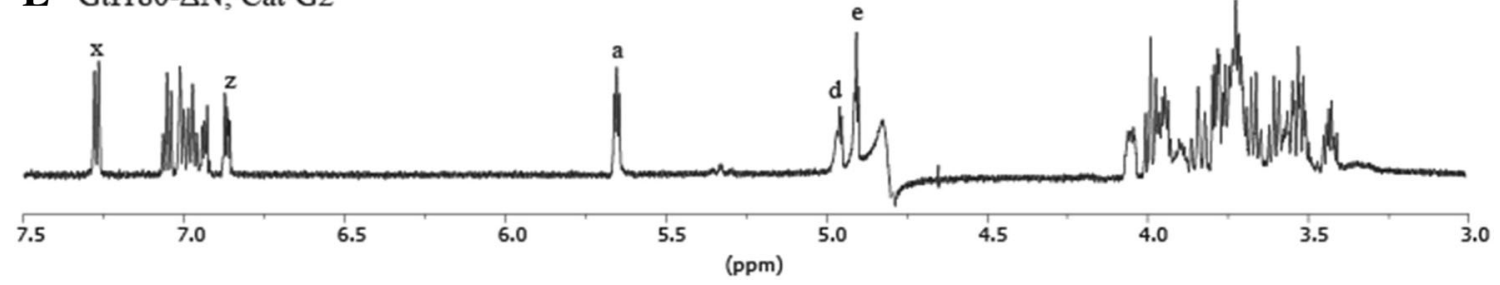

Fig. 5 One-dimensional ${ }^{1} \mathrm{H}$ NMR spectra of catechol glucosides produced by a GtfA- $\Delta \mathrm{N}$ with $100 \mathrm{mM}$ catG1 and $1000 \mathrm{mM}$ sucrose, b GtfA- $\Delta \mathrm{N}$ with $100 \mathrm{mM}$ catG1, c GtfA- $\Delta \mathrm{N}$ with cat ${ }^{4} \mathrm{G} 2$, d Gtf180- $\Delta \mathrm{N}$

\section{Use of di-glucosylated catechol as glucosyl donor/acceptor substrate}

Incubations with $100 \mathrm{mM}$ cat ${ }^{4} \mathrm{G} 2$ as sole substrate showed that GtfA- $\Delta \mathrm{N}$ also used di-glucosylated catechol as donor/acceptor substrate, although with a rate (2.3 U/mg GtfA- $\Delta \mathrm{N}$ ) that was $\sim 75 \%$ lower than on catG1 $(10.5 \mathrm{U} / \mathrm{mg})$ and $\sim 90 \%$ lower than on sucrose (28.5 U/mg) (Fig. 7). NP-HPLC analysis showed that cat $^{4} \mathrm{G} 2$ was converted to catG1, free catechol, and catechol glucosides with three and more glucose units attached (Supplemental material, Fig. S6).

To test whether the glucosidic linkage type of catG1 had an effect on the transglucosylation rate of GtfA- $\Delta N$, incubations were also performed with $(\alpha 1 \rightarrow 3)$ - and $(\alpha 1 \rightarrow 6)$-linked catechol di-glucosides. GtfA- $\Delta \mathrm{N}$ showed some activity on cat $^{3} \mathrm{G} 2(0.16 \pm 0.01 \mathrm{U} / \mathrm{mg}$ GtfA- $\Delta \mathrm{N})$, with cat ${ }^{3} \mathrm{G} 2$, and e Gtf180- $\Delta \mathrm{N}$ with cat $^{6} \mathrm{G} 2$. Peaks are marked with structural-reporter-group signals derived from te Poele et al. (2016) and Devlamynck et al. (2016), shown in Fig. 6

but showed no significant activity with cat $^{6} \mathrm{G} 2$ (Fig. 7). Gtf180- $\Delta \mathrm{N}$ used both cat $^{3} \mathrm{G} 2$ and cat $^{6} \mathrm{G} 2$ as donor/ acceptor substrates, at $0.34 \pm 0.04$ and $1.04 \pm 0.12 \mathrm{U} /$ mg Gtf180- $\Delta \mathrm{N}$, respectively, but in this case, activity with cat ${ }^{4} \mathrm{G} 2$ was not significant (Fig. 7). GtfMLI- $\Delta \mathrm{N}$ showed no significant activity with the three catechol di-glucosides (Fig. 7). 1D ${ }^{1} \mathrm{H}$ NMR analysis of the Cat ${ }^{4} \mathrm{G} 2$-derived products following incubation with GtfA- $\Delta \mathrm{N}$ (Fig. 5c) showed a product spectrum containing $(\alpha 1 \rightarrow 4)$ (peaks b, $\mathrm{c}$, and $\mathrm{f}$ ) and $(\alpha 1 \rightarrow 6)$ (peaks $\mathrm{d}$ and e) glucosidic linkages. Incubation of $\mathrm{Cat}^{3} \mathrm{G} 2$ with Gtf180- $\Delta \mathrm{N}$ yielded products with $(\alpha 1 \rightarrow 3)$ (peaks $\mathrm{i}$ and $\mathrm{g}),(\alpha 1 \rightarrow 4)$ (peaks $\mathrm{b}, \mathrm{c}$, and $\mathrm{f}$ ), and $(\alpha 1 \rightarrow 6)$ (peaks $\mathrm{d}$ and e) glucosidic linkages (Fig. 5d). Incubation of Cat $^{6} \mathrm{G} 2$ with Gtf180- $\Delta \mathrm{N}$ resulted in a product spectrum with only $(\alpha 1 \rightarrow 6)$ (peaks $\mathrm{d}$ and e) glucosidic linkages (Fig. 5e). 
Fig. 6 Overview of structuralreporter-group signals derived from te Poele et al. (2016) and Devlamynck et al. (2016) used for interpretation of $1 \mathrm{D}^{1} \mathrm{H}$ NMR spectra

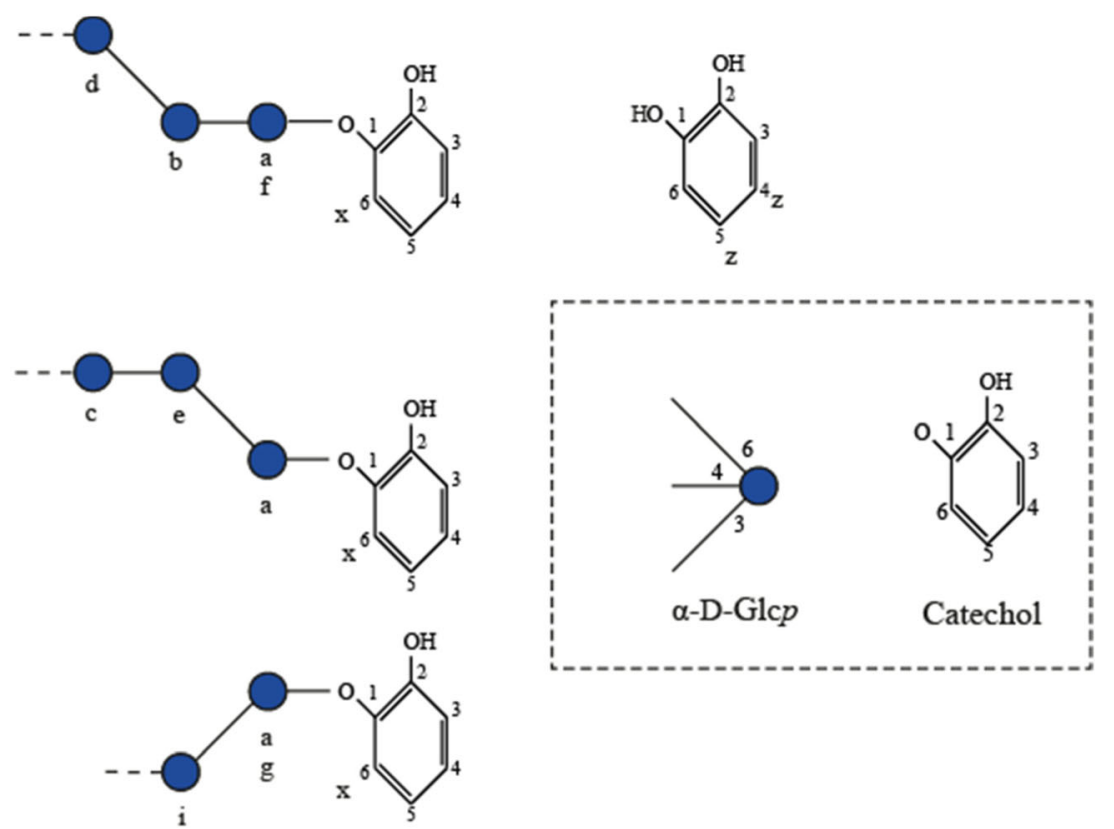

\section{Discussion}

In this study, we show that the glucansucrase GtfA- $\Delta \mathrm{N}$ of L. reuteri 121 rapidly glucosylated catechol with sucrose as donor substrate. Upon sucrose depletion, the enzyme used several catechol glucosides as glucosyl donor/acceptor substrate. Especially mono-glucosylated catechol is an effective donor/acceptor substrate for GtfA- $\Delta \mathrm{N}$. This enzyme also efficiently used the mono-glucosides of several other phenolic compounds, such as pyrogallol and ethyl gallate as donor/ acceptor substrates. Also the related $L$. reuteri enzymes, Gtf180- $\Delta \mathrm{N}$ and GtfMLI- $\Delta \mathrm{N}$, use these phenolic monoglucosides efficiently as donor/acceptor substrates. Notably, cat $^{4} \mathrm{G} 2$ also functioned as donor substrate for GtfA- $\Delta \mathrm{N}$, while cat $^{3} \mathrm{G} 2$ and cat ${ }^{6} \mathrm{G} 2$ were donor substrates for Gtf180- $\Delta \mathrm{N}$. The $(\alpha 1 \rightarrow 4)$-linked di-glucosylated catechol was converted into
catG1, free catechol, and catechol glucosides with three and more glucose units attached (Fig. 3). GtfA- $\Delta \mathrm{N}$ first cleaves the glycosidic bond between the two glucose moieties of the cat $^{4} \mathrm{G} 2$ donor substrate and then the bond between the first glucose and the catechol moiety of the resulting catG1. GtfA- $\Delta \mathrm{N}$ appears unable to cleave of the two glucose units at once, since (besides catechol glucosides with an even number of glucose units) also catG1 and catechol glucosides with an uneven number of glucose units were detected (Supplemental material, Fig. S2). The donor binding pocket of the active site of GtfA- $\Delta \mathrm{N}$ is most likely too small to bind sugars with more than one glucose unit, like maltose. The high-resolution crystal structure of the closely related Gtf180- $\Delta \mathrm{N}$ (78\% amino acid identity) with sucrose bound in the active site, shows that the donor binding cavity is blocked beyond subsite -1 where the glucose moiety of
Fig. 7 Effects of the glucosidic linkage type of di-glucosylated catechol on the initial enzyme activity in the reaction buffer and $1.25 \mathrm{mg} / \mathrm{mL}$ GtfA- $\Delta \mathrm{N}$, Gtf180$\Delta \mathrm{N}$, and GtfMLI- $\Delta \mathrm{N}$ at $37^{\circ} \mathrm{C}$ and $\mathrm{pH}$ 4.7. The data represent the means of two independent enzyme activity assays; cat $^{3} \mathrm{G} 2$ (white bar); cat $^{4} \mathrm{G} 2$ (black bar); cat ${ }^{6} \mathrm{G} 2$ (grey bar). Error bars are \pm 1 standard deviation

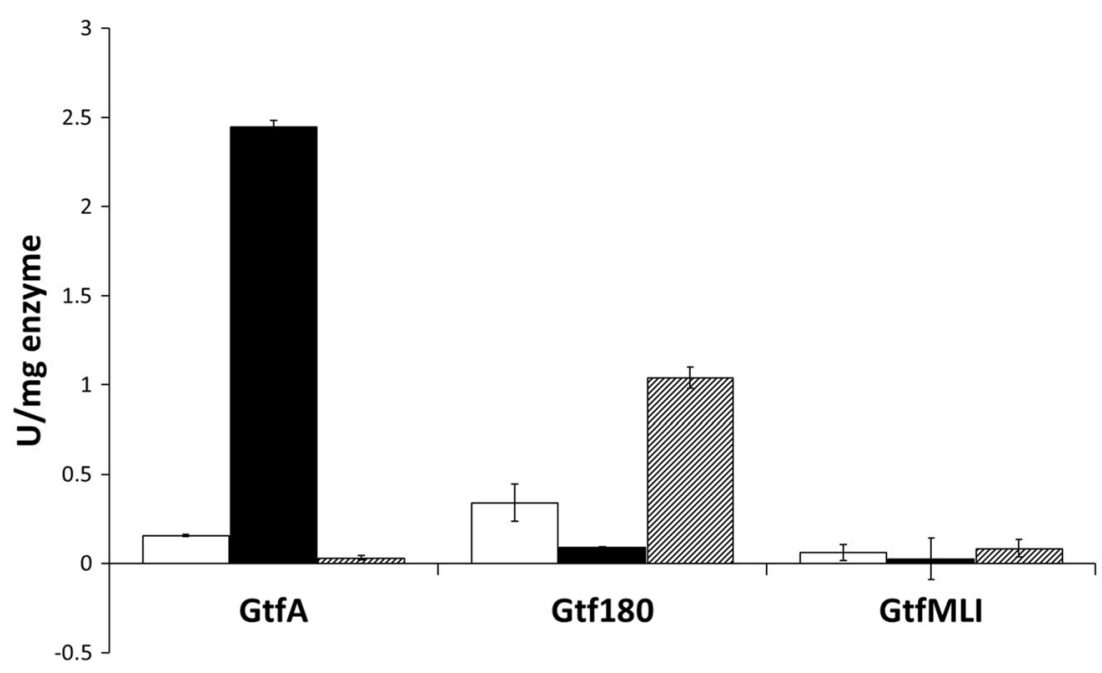


sucrose binds, and is therefore unable to bind longer oligosaccharides (Vujičić-Žagar et al. 2010). Recently, also the crystal structure of GtfA- $\Delta \mathrm{N}$ was determined at $3.6 \AA$ resolution by molecular replacement (Pijning et al. 2012). Superposition of the three-dimensional structure of GtfA- $\Delta \mathrm{N}$ with the Gtf180- $\Delta \mathrm{N}$ sucrose complex showed that the active site of GtfA- $\Delta \mathrm{N}$ is almost identical to that of Gtf180- $\Delta \mathrm{N}$ (Pijning et al. 2012). The three amino acids that are responsible for blocking the binding cavity in Gtf180- $\Delta \mathrm{N}$ are conserved in GtfA- $\Delta \mathrm{N}$, and in all other family GH70 enzymes. This suggests that binding of a single glucose residue in subsite -1 is a general property of all glucansucrase enzymes in family GH70 (Vujičić-Žagar et al. 2010).

Compared to cat ${ }^{4} \mathrm{G} 2$, GtfA- $\Delta \mathrm{N}$ showed minor activity on cat $^{3} \mathrm{G} 2$, and had no significant activity on cat $^{6} \mathrm{G} 2$. Gtf180- $\Delta \mathrm{N}$, on the contrary, uses both $(\alpha 1 \rightarrow 3)$ - and $(\alpha 1 \rightarrow 6)$-linked diglucosylated catechol as glucosyl donor, but not the $(\alpha 1 \rightarrow 4)$ linked variant. The hydrolysis energies of the $(\alpha 1 \rightarrow 3),(\alpha 1 \rightarrow$ $4)$, and $(\alpha 1 \rightarrow 6)$ linkages between the two glucoses of $\alpha$-DGlcp-( $1 \rightarrow \mathrm{x}) \alpha$-D-Glcp-catechol (catG2) are clearly lower than for sucrose, as evidenced by lower enzyme activities on the catG2 substrates, but apparently high enough to drive the glucansucrase-catalyzed donor reactions with these compounds. GtfA- $\Delta \mathrm{N}$ thus uses cat ${ }^{4} \mathrm{G} 2$ as glucosyl donor, but as previously shown, maltose is not a donor substrate (Dobruchowska et al. 2013). The glucosylated phenolic compounds can be regarded as activated sugar donors, like $p$ nitrophenyl- $\alpha$-glucoside (pNPG), since the aromatic ring functions as an excellent leaving group during the glucosyl transfer reaction (Andre et al. 2010). The presence of the catechol group most likely increases the hydrolysis energy of the $(\alpha 1 \rightarrow 4)$ glycosidic linkage to allow the transglycosylation reaction to occur. Previously, the free energies of enzymatic hydrolysis $\left(\Delta \mathrm{G}^{0}\right)$ of sucrose, maltose, and isomaltose have been experimentally determined as $-26.5,-15.5$, and $-7.06 \mathrm{~kJ} / \mathrm{mol}$, respectively, using NP-HPLC and microcalorimetry (Goldberg et al. 1989; Tewari and Goldberg 1989). In future research, it would be interesting to calculate the free energies of hydrolysis of the newly formed catechol glucoside compounds. Apparently, the hydrolysis energy of the glucosidic linkages in cat $\mathrm{G} 2$ is not the only factor that determines which catG2 the specific glucansucrase enzymes can use, since GtfA- $\Delta \mathrm{N}$ can use cat $^{4} \mathrm{G} 2$ as glycosyl donor, but Gtf180- $\Delta \mathrm{N}$ cannot. Similarly, Gtf1 $80-\Delta \mathrm{N}$ uses the $(\alpha 1 \rightarrow 6)$-linked variant, but GtfA- $\Delta \mathrm{N}$ does not. With sucrose only, GtfA- $\Delta \mathrm{N}$ synthesizes a glucan with mostly $(\alpha 1 \rightarrow 4)$ and $(\alpha 1 \rightarrow 6)$ glucosidic bonds in a 58:42 ratio (van Leeuwen et al. 2008b), whereas Gtf180- $\Delta \mathrm{N}$ prefers the synthesis of $(\alpha 1 \rightarrow 6)$ and $(\alpha 1 \rightarrow 3)$ glycosidic linkages in a 69:31 ratio (van Leeuwen et al. 2008a). The catG2 specificity of the glucansucrase enzymes thus appears to depend on both the hydrolysis energy of the glycosidic linkage of the substrate and the glucoside linkage specificity of the enzyme. Molecular dynamic studies are currently performed to get more insight in how mono- and di-glucosylated catechol are positioned in the donor binding cavity of the active site of GtfA- $\Delta \mathrm{N}$ and Gtf180- $\Delta \mathrm{N}$.

It was assumed that glucansucrases have a limited promiscuity toward their glucosyl donor substrates (Andre et al. 2010). Only some early studies have reported the use of glucosyl donors other than sucrose by glucansucrases. Hehre and Suzuki (1966) found that dextransucrases of different Leuconostoc mesenteroides strains readily transferred the glucose moiety from sucrose to lactulose to produce lactulosucrose, but also that these enzymes utilized the glucose of lactulosucrose almost as efficiently as sucrose for the synthesis of dextran polymers. Glucansucrases from Leuconostoc and Streptococcus could also polymerize the glucosyl group of $\alpha$-D-Glcp-fluoride (Genghof and Hehre 1972; Figures and Edwards 1976; Jung and Mayer 1981), $\alpha$ D-Glcp- $\alpha$-L-sorbofuranoside (Streptococcus mutans) (Mazza et al. 1975) and $p$-nitrophenyl $\alpha$-D-glucopyranoside (pNPG) (Binder and Robyt 1983). With pNPG, the initial rate of release of $p$-nitrophenol from $\mathrm{pNPG}$ was $\sim 100$-fold lower than the initial rate of glucose incorporation into dextran from sucrose. Binder et al. (1983) showed that these glucansucrases also use several gluco-oligosaccharides, i.e., isomaltotriose, panose, maltotriose, and dextran as D-glucosyl donors and as acceptor substrates. When these gluco-oligosaccharides also acted as glucosyl acceptor substrates, disproportionation reactions occurred. From isomaltotriose, for example, isomaltose and isomaltotetraose were formed initially, and a series of isomalto-oligosaccharides were synthesized eventually.

Our findings show that glucansucrase enzymes from L. reuteri are more promiscuous towards glucosyl donor substrates as well. This may therefore be a general feature of glucansucrases and will have a severe impact on the final glucosylation yield of acceptor substrates, as observed with GtfA- $\Delta \mathrm{N}$ and catechol upon prolonged incubation. Under the selected incubation conditions, the yield of catechol glucosylation was $100 \%$ after $30 \mathrm{~min}$, but after $4 \mathrm{~h}$ the yield had decreased to $\sim 50 \%$ due to de-glucosylation of catG1 and $\mathrm{cat}^{4} \mathrm{G} 2$ to catechol. The decrease in yield is even more pronounced when lower initial sucrose concentrations are used. In that case, with the same amount of enzyme and catechol, sucrose is depleted much earlier. At the time point of sucrose depletion, relatively more mono-glucosylated catechol that has not been further glucosylated to higher-DP glucosides is present, compared to incubations with higher sucrose concentrations. Since GtfA- $\Delta \mathrm{N}$ can also use catG1 and cat ${ }^{4} \mathrm{G} 2$ as alternative glucosyl donors, more catechol will be reformed at lower sucrose concentrations, resulting in lower catechol conversion yields overall. Prolonged incubation beyond the time point of sucrose depletion thus may result in deglucosylation of glycosides; reported yields for acceptor substrate reactions of glucansucrases may therefore be an underestimation. 
We show that the studied glucansucrase enzymes efficiently glucosylate several phenolic compounds and that they use the produced glucosylated phenolics as glucosyl donor when sucrose is depleted. In case of catechol glucosides, the G2 products also served as glucosyl donors, but they were less efficient than the mono-glucosylated catechol.

Acknowledgements We thank Geralt ten Kate for the HPAEC analysis. The authors wish to thank the EU Project NOVOSIDES FP7-KBBE-543 2010-4-265854 (to EMtP and LD) and the Ubbo Emmius Fund of the University of Groningen and the Special Research Fund (BOF) of Ghent University ( $\mathrm{PhD}$ scholarship to $\mathrm{TD}$ ) for the financial support. VV and SSvL were funded by the University of Groningen.

\section{Compliance with ethical standards}

Conflict of interest The authors declare that they have no conflict of interest.

Ethical statement This article does not contain any studies with human participants or animals performed by any of the authors.

Open Access This article is distributed under the terms of the Creative Commons Attribution 4.0 International License (http:// creativecommons.org/licenses/by/4.0/), which permits unrestricted use, distribution, and reproduction in any medium, provided you give appropriate credit to the original author(s) and the source, provide a link to the Creative Commons license, and indicate if changes were made.

\section{References}

Andre I, Potocki-Véronèse G, Morel S, Monsan P, Remaud-Siméon M (2010) Sucrose-utilizing transglucosidases for biocatalysis. Top Curr Chem 294:25-48

Binder TP, Robyt JF (1983) $p$-Nitrophenyl $\alpha$-D-glucopyranoside, a new substrate for glucansucrases. Carbohydr Res 124:287-299

Binder TP, Cote GL, Robyt JF (1983) Disproportionation reactions catalyzed by Leuconostoc and Streptococcus glucansucrases. Carbohydr Res 124:275-286

Cote GL, Robyt JF (1982) Acceptor reactions of alternansucrase from Leuconostoc mesenteroides NRRL B-1355. Carbohydr Res 111: $127-142$

Desmet T, Soetaert W, Bojarová P, Křen V, Dijkhuizen L, Eastwick-Field V, Schiller A (2012) Enzymatic glycosylation of small molecules: challenging substrates require tailored catalysts. Chemistry 18: 10786-10801. doi:10.1002/chem.201103069

Devlamynck T, te Poele EM, Meng X, van Leeuwen SS, Dijkhuizen L (2016) Glucansucrase Gtf180- $\Delta \mathrm{N}$ of Lactobacillus reuteri 180: enzyme and reaction engineering for improved glycosylation of noncarbohydrate molecules. Appl Microbiol Biotechnol 100:75297539. doi:10.1007/s00253-016-7476-X

Dobruchowska JM, Meng X, Leemhuis H, Gerwig GJ, Dijkhuizen L, Kamerling JP (2013) Gluco-oligomers initially formed by the reuteransucrase enzyme of Lactobacillus reuteri 121 incubated with sucrose and malto-oligosaccharides. Glycobiology 23:1084-1096. doi:10.1093/glycob/cwt048

Figures W, Edwards J (1976) $\alpha$-D-Glucopyranosyl fluoride as a Dglucopyranosyl donor for a glycosyltransferase complex from Streptococcus mutans FA1. Carbohydr Polym 48:245-253

van Geel-Schutten GH, Faber EJ, Smit E, Bonting K, Smith MR, Ten Brink B, Kamerling JP, Vliegenthart JFG, Dijkhuizen L (1999)
Biochemical and structural characterization of the glucan and fructan exopolysaccharides synthesized by the Lactobacillus reuteri wild-type strain and by mutant strains. Appl Environ Microbiol 65: 3008-3014

Genghof D, Hehre E (1972) De novo glycosidic linkage synthesis by glycosylases: $\alpha$-D-fluoride polymerization by dextransucrase (36662). Proc Sot Exp Biol Med 140:1298-1301

Goldberg RN, Tewaril YB, Ahluwalia JC (1989) Thermodynamics of the hydrolysis of sucrose. J Biol Chem 264:9901-9904

Hehre EJ, Suzuki H (1966) New reactions of dextransucrase: $\alpha$-Dglucosyl transfers to and from the anomeric sites of lactulose and fructose. Arch Biochem Biophys 113:675-683

Jung SM, Mayer RM (1981) Dextransucrase: donor substrate reactions. Arch Biochem Biophys 208:288-295

Kim Y-M, Yeon MJ, Choi N-S, Chang Y-H, Jung MY, Song JJ, Kim JS (2010) Purification and characterization of a novel glucansucrase from Leuconostoc lactis EG001. Microbiol Res 165:384-391. doi: 10.1016/j.micres.2009.08.005

Kralj S, van Geel-Schutten GH, Rahaoui H, Leer RJ, Faber EJ, van der Maarel MJEC, Dijkhuizen L (2002) Molecular characterization of a novel glucosyltransferase from Lactobacillus reuteri strain 121 synthesizing a unique, highly branched glucan with $\alpha-(1-4)$ and $\alpha(1-6)$ glucosidic bonds. Appl Environ Microbiol 68:4283-4291. doi:10. 1128/AEM.68.9.4283

Kralj S, van Geel-Schutten GH, Dondorff MMG, Kirsanovs S, van der Maarel MJEC, Dijkhuizen L (2004a) Glucan synthesis in the genus Lactobacillus: isolation and characterization of glucansucrase genes, enzymes and glucan products from six different strains. Microbiology 150:3681-3690. doi:10.1099/mic.0.27321-0

Kralj S, van Geel-Schutten GH, van der Maarel MJEC, Dijkhuizen L (2004b) Biochemical and molecular characterization of Lactobacillus reuteri 121 reuteransucrase. Microbiology 150: 2099-2112. doi:10.1099/mic.0.27105-0

Leemhuis H, Pijning T, Dobruchowska JM, Dijkstra BW, Dijkhuizen L (2012) Glycosidic bond specificity of glucansucrases: on the role of acceptor substrate binding residues. Biocatal Biotransformation 30: 366-376. doi:10.3109/10242422.2012.676301

Leemhuis H, Pijning T, Dobruchowska JM, van Leeuwen SS, Kralj S, Dijkstra BW, Dijkhuizen L (2013) Glucansucrases: threedimensional structures, reactions, mechanism, $\alpha$-glucan analysis and their implications in biotechnology and food applications. J Biotechnol 163:250-272. doi:10.1016/j.jbiotec.2012.06.037

van Leeuwen SS, Kralj S, van Geel-Schutten IH, Gerwig GJ, Dijkhuizen L, Kamerling JP (2008a) Structural analysis of the $\alpha$-D-glucan (EPS180) produced by the Lactobacillus reuteri strain 180 glucansucrase GTF180 enzyme. Carbohydr Res 343:1237-1250. doi:10.1016/j.carres.2008.01.042

van Leeuwen SS, Kralj S, van Geel-Schutten IH, Gerwig GJ, Dijkhuizen L, Kamerling JP (2008b) Structural analysis of the $\alpha$-D-glucan (EPS35-5) produced by the Lactobacillus reuteri strain 35-5 glucansucrase GTFA enzyme. Carbohydr Res 343:1251-1265. doi:10.1016/j.carres.2008.01.044

Lombard V, Golaconda Ramulu H, Drula E, Coutinho PM, Henrissat B (2014) The carbohydrate-active enzymes database (CAZy) in 2013. Nucleic Acids Res 42:D490-D495. doi:10.1093/nar/gkt1178

Mayer RM (1987) Dextransucrase: a glucosyltransferase from Streptococcus sanguis. Methods Enzymol 138:649-661

Mazza JC, Akgerman A, Edwards JR (1975) Synthesis of $\alpha$-Dglycopyranosyl $\alpha$-L-sorbofuranoside, and its use as a D-glucosyl donor. Carbohydr Res 40:402-406

Meng X, Dobruchowska JM, Pijning T, López CA, Kamerling JP, Dijkhuizen L (2014) Residue Leu940 has a crucial role in the linkage and reaction specificity of the glucansucrase GTF180 of the probiotic bacterium Lactobacillus reuteri 180. J Biol Chem 289: 32773-32782. doi:10.1074/jbc.M114.602524 
Meulenbeld GH, Hartmans S (2000) Transglycosylation by Streptococcus mutans GS-5 glucosyltransferase-D: acceptor specificity and engineering of reaction conditions. Biotechnol Bioeng 70: 363-369. doi:10.1002/1097-0290(20001120)70:4<363::AIDBIT1>3.0.CO;2-2

Monsan P, Remaud-Siméon M, André I (2010) Transglucosidases as efficient tools for oligosaccharide and glucoconjugate synthesis. Curr Opin Microbiol 13:293-300. doi:10.1016/j.mib.2010.03.002

Pijning T, Vujičić-Žagar A, Kralj S, Dijkhuizen L, Dijkstra BW (2012) Structure of the $\alpha-1,6 / \alpha-1,4$-specific glucansucrase GTFA from Lactobacillus reuteri 121 . Acta Crystallogr Sect F Struct Biol Cryst Commun 68:1448-1454. doi:10.1107/S1744309112044168

te Poele EM, Grijpstra P, van Leeuwen SS, Dijkhuizen L (2016) Glucosylation of catechol with GTFA glucansucrase enzyme from Lactobacillus reuteri, using sucrose as donor substrate. Bioconjug Chem 27:937-946. doi:10.1021/acs.bioconjchem.6b00018
Seibel J, Hellmuth H, Hofer B, Kicinska A-M, Schmalbruch B (2006) Identification of new acceptor specificities of glycosyltransferase $\mathrm{R}$ with the aid of substrate microarrays. Chembiochem 7:310-320. doi:10.1002/cbic.200500350

Seo E-S, Kang J, Lee J-H, Kim G-E, Kim GJ, Kim D (2009) Synthesis and characterization of hydroquinone glucoside using Leuconostoc mesenteroides dextransucrase. Enzym Microb Technol 45:355-360. doi:10.1016/j.enzmictec.2009.07.011

Tewari YB, Goldberg RN (1989) Thermodynamics of hydrolysis of disaccharides. Cellobiose, gentiobiose, isomaltose, and maltose. J Biol Chem 264:3966-3971

Vujičić-Žagar A, Pijning T, Kralj S, López CA, Eeuwema W, Dijkhuizen L, Dijkstra BW (2010) Crystal structure of a $117 \mathrm{kDa}$ glucansucrase fragment provides insight into evolution and product specificity of GH70 enzymes. Proc Natl Acad Sci U S A 107:21406-21411. doi: 10.1073/pnas. 1007531107 